\title{
Investigating the role of MRGPRC11 and capsaicin-sensitive afferent nerves in the anti-influenza effects exerted by SLIGRL- amide in murine airways
}

\author{
Amy Y. Chang ${ }^{1,2}$, Tracy S. Mann ${ }^{1}$, Peter K. McFawn², Liang Han ${ }^{3}$, Xinzhong Dong ${ }^{3}$ and Peter J. Henry ${ }^{1 *}$
}

\begin{abstract}
Background: The hexapeptide SLIGRL-amide activates protease-activated receptor-2 (PAR-2) and mas-related G protein-coupled receptor C11 (MRGPRC11), both of which are known to be expressed on populations of sensory nerves. SLIGRL-amide has recently been reported to inhibit influenza A (IAV) infection in mice independently of PAR-2 activation, however the explicit roles of MRGPRC11 and sensory nerves in this process are unknown. Thus, the principal aim of this study was to determine whether SLIGRL-amide-induced inhibition of influenza infection is mediated by MRGPRC11 and/or by capsaicin-sensitive sensory nerves.
\end{abstract}

Methods: The inhibitory effect of SLIGRL-amide on IAV infection observed in control mice in vivo was compared to effects produced in mice that did not express MRGPRC11 (mrgpr-cluster ${ }^{-/-}$mice) or had impaired sensory nerve function (induced by chronic pre-treatment with capsaicin). Complementary mechanistic studies using both in vivo and ex vivo approaches investigated whether the anti-IAV activity of SLIGRL-amide was (1) mimicked by either activators of MRGPRC11 (BAM8-22) or by activators (acute capsaicin) or selected mediators (substance P, CGRP) of sensory nerve function, or (2) suppressed by inhibitors of sensory nerve function (e.g. NK1 receptor antagonists).

Results: SLIGRL-amide and BAM8-22 dose-dependently inhibited IAV infection in mrgpr-cluster $\Delta^{-1-}$ mice that do not express MRGPRC11. In addition, SLIGRL-amide and BAM8-22 each inhibited IAV infection in capsaicin-pre-treated mice that lack functional sensory nerves. Furthermore, the anti-IAV activity of SLIGRL-amide was not mimicked by the sensory neuropeptides substance P or CGRP, nor blocked by either NK1 (L-703,606, RP67580) and CGRP receptor (CGRP8-37) antagonists. Direct stimulation of airway sensory nerves through acute exposure to the TRPV1 activator capsaicin also failed to mimic SLIGRL-amide-induced inhibition of IAV infectivity. The anti-IAV activity of SLIGRL-amide was mimicked by the purinoceptor agonist ATP, a direct activator of mucus secretion from airway epithelial cells. Additionally, both SLIGRL-amide and ATP stimulated mucus secretion and inhibited IAV infectivity in mouse isolated tracheal segments.

Conclusions: SLIGRL-amide inhibits IAV infection independently of MRGPRC11 and independently of capsaicin-sensitive, neuropeptide-releasing sensory nerves, and its secretory action on epithelial cells warrants further investigation.

Keywords: SLIGRL-amide, Influenza, Airway sensory nerves, Capsaicin, Mas-related G protein-coupled receptor C11, Neuropeptides, Mucin

\footnotetext{
* Correspondence: peter.henry@uwa.edu.au

Amy Y. Chang and Tracy S. Mann are joint first authors

${ }^{1}$ School of Medicine and Pharmacology, University of Western Australia,

Crawley, WA 6009, Australia

Full list of author information is available at the end of the article
} 


\section{Background}

Worldwide, influenza A virus (IAV) infections are estimated to cause up to 5 million cases of severe illness, and between 250,000 and 500,000 deaths each year [1]. The potentially devastating impact of seasonal influenza epidemics is lessened through vaccination, which significantly reduces the rate of hospitalisation and death from influenza. Unfortunately, annual vaccination does not provide protection against irregular influenza pandemics caused by antigenically novel strains of IAV transmitted from other animal species. Thus, considerable effort has been directed towards preventing and treating IAV infection with antiviral agents including the neuraminidase inhibitors oseltamivir (Tamiflu) and zanamivir (Relenza) $[2,3]$. Despite these efforts, our capacity to control influenza infection remains threatened due to the rapid emergence of resistance to oseltamivir and other conventional antiviral agents such as the adamantanes [4-6]. Hence, there is an urgent unmet need to identify new anti-viral drugs to provide a frontline defence to infection, especially in the event of an unpredictable but inevitable influenza pandemic.

Our laboratory has recently shown that the hexapeptidic sequence SLIGRL-amide (Ser-Leu-Ile-Gly-Arg-Leu- $\mathrm{NH}_{2}$ ) inhibits IAV infection in mice [7]. SLIGRL-amide is a well-established activator of protease-activated receptor-2 (PAR-2) [8]. However, SLIGRL-amide inhibits IAV infection independently of PAR-2 as anti-viral effects were preserved in PAR2 (-/-) mice [7]. SLIGRL-amide has also been reported to activate MRGPRC11, a subtype of MASrelated G protein-coupled receptor (MRGPR) [8-10]. Whether SLIGRL-amide inhibits IAV infection via MRGPRC11 is currently unknown.

The MRGPR family comprises approximately 40 members that are grouped into nine subfamilies (MRGPRA to $-\mathrm{H}$, and $-\mathrm{X})$, based on sequence similarities. Subfamilies $\mathrm{A}, \mathrm{B}, \mathrm{C}$, and $\mathrm{H}$ exist only in rodents, whereas subfamily $\mathrm{X}$ is specific to primates including humans [10]. Mouse and rat MRGPRC have been found to exhibit high similarities with human MRGPRX1 in terms of expression pattern, sequence homology and binding profile [11-14]. For example, both rodent MRGPRC11 and human MRGPRX1 are activated by the agonist BAM822. The expression of these receptors is primarily restricted to the small-diameter nociceptive sensory neurons $[11,12,15,16]$.

Sensory nerves of the respiratory system innervate a range of important structures, including the airway epithelium, submucosal glands and airway smooth muscle [17]. The predominant subtype of airway sensory nerve is the vagal bronchopulmonary $\mathrm{C}$-fibre, whose cell bodies are located within the jugular and nodose ganglia [18]. Jugular C-fibres are more likely to innervate the upper airways [19] and to express neuropeptides when activated [20]. Noxious substances such as the TRPV1 activator capsaicin can activate populations of sensory nerves and may promote the release of neuropeptides such as substance P and CGRP via an axonal reflex [21]. Released neuropeptides, via activation of their cognate neurokinin (NK) and CGRP receptors, can in turn induce a wide range of biological effects, such as increased cilia beating and mucus secretion [22]. Several components of mucus, including surfactants, secretory IgA, defensins and MUC5B mucin have been reported to exhibit anti-IAV activities [23].

Thus far, the molecular target mediating the anti-IAV effects of SLIGRL-amide is unknown. The current study tests the hypotheses that SLIGRL-amide inhibits IAV infection by activating MRGPRC11, and that the antiviral effects of SLIGRL-amide are mediated by neuropeptides, which stimulate the secretion of endogenous substances with anti-IAV activities from mucus-producing airway cells. If the hypotheses are correct, then SLIGRL-amide induced anti-IAV effects should be mimicked by activators of MRGPRC11 (such as BAM8-22) and by exogenous neuropeptides (such as substance P and CGRP), as well as by other stimuli that directly activate sensory nerves (TRPV1 activator capsaicin). Furthermore, the anti-IAV effects of SLIGRL-amide should be reduced in mice lacking MRGPRC11 (Mrgpr-cluster $\Delta^{-/-}$mice, [8, 24]) and by processes (capsaicin-induced desensitisation) or agents (neurokinin receptor antagonists) that suppress sensory nerve function. In the current study, the effect of these interventions on SLIGRL-amide-induced anti-IAV activity was tested using a combination of in vivo (airway inflammation in IAV-exposed mice) and novel ex vivo approaches (immunohistochemical staining for IAV in viable perfused tracheal explants; [7]). Utilisation of ex vivo approaches also facilitated preliminary investigations of the anti-IAV activity of SLIGRL-amide in human isolated airways.

\section{Methods}

Ethics statement

All in vivo animal studies were conducted with the approval of the University of Western Australia Animal Ethics Committee (approval number RA/3/100/1258) and strictly adhered to the guidelines stipulated in the "Australian code for the care and use of animals for scientific purposes 8th Edition 2013", published by the National Health and Medical Research Council of Australia. In accordance with the National Health and Medical Research Council of Australia's National Statement on Ethical Conduct in Human Research 2007, segments of human lung tissue were obtained with informed written consent from patients undergoing lobectomy at two West Australian hospitals, Sir Charles Gairdner Hospital and the Mount Hospital. These 
studies were specifically approved by the Sir Charles Gairdner Hospital Human Research Ethics Committee (approval number 2011-128), the Mount Hospital Ethics Committee (approval number EC71.1) and The University of Western Australia Human Ethics Office (approval numbers RA/4/1/7256 and RA/4/1/7220).

\section{Influenza virus}

Mouse-adapted influenza A/PR/8/34 virus was propagated in the allantoic fluid of 9-day old embryonated chicken eggs (Altona Hatchery, Forrestfield, Australia) at $37{ }^{\circ} \mathrm{C}$ for 3 days, as described previously [25]. Viral infectivity was assessed using allantois-on-shell titration and quantitated via hemagglutination assay [26]. The TCID50 of the harvested allantoic fluid was $10^{-5.8} / \mathrm{ml}$.

\section{In vivo infection of mice with IAV}

Unless otherwise stated, male BALB/c mice (specified pathogen-free) aged 7 to 8 weeks (Animal Resource Centre, Murdoch, WA) were housed at the University of Western Australia Animal Care Unit under a 12 h light/ dark cycle and received food and water ad libitum. The role of MGRPRC11 in SLIGRL-amide-induced anti-IAV activity was investigated using Mrgpr-cluster ${ }^{-/-}$and wild-type mice, generated as previously described [24]. Groups of mice were lightly anaesthetised (methoxyflurane) and intranasally (i.n.) inoculated with a $20 \mu \mathrm{l}$ solution containing (a) influenza A/PR/8/34 virus (1:800 dilution of stock IAV) alone, (b) IAV plus peptide (SLIGRL-amide, SLIGR-amide, BAM8-22) or (c) 1:800 dilution of allantoic fluid (vehicle). Mice were killed with an overdose of pentobarbitone $(160 \mathrm{mg} / \mathrm{kg}$ i.p. injection) at day 4 postinoculation for determination of IAV-induced inflammation using differential cell counting of leukocytes recovered from bronchoalveolar lavage (BAL) fluid [7].

\section{Bronchoalveolar lavage}

BAL was performed by intratracheal instillation of $2.5 \mathrm{ml}$ of cold phosphate-buffered saline (PBS) pH 7.4, in $0.5 \mathrm{ml}$ volumes via a tracheal cannula. After each instillation, BAL fluid was recovered, pooled and centrifuged at $400 \times g$ for $5 \mathrm{mins}$ at $4{ }^{\circ} \mathrm{C}$. Supernatant was removed and the cell pellet resuspended in PBS $+1.0 \%$ bovine serum albumin. Total cell counts and viability were determined by use of a haemocytometer and $0.4 \%$ trypan blue exclusion. Cytospin preparations of each cell sample were stained with DIFF-Quik (Thermo Fisher Scientific, Waltham, MA), and differential cell counts of macrophages, neutrophils, eosinophils and lymphocytes were determined by counting 400 cells under a light microscope using standard morphological criteria.

\section{Capsaicin-induced attenuation of sensory nerve function in mice}

Administration of multiple subcutaneous injections of capsaicin to anaesthetised mice is an effective means of impairing sensory nerve function [27-30]. On day one, mice were anaesthetized $(130 \mathrm{mg} / \mathrm{kg}$ ketamine and $13 \mathrm{mg} / \mathrm{kg}$ xylazine, i.p.) and administered the bronchodilators terbutaline $(0.1 \mathrm{mg} / \mathrm{kg}$, i.p. $)$ and theophylline $(10 \mathrm{mg} / \mathrm{kg}$, s.c.). Twenty mins later, mice were injected subcutaneously with capsaicin $(25 \mathrm{mg} / \mathrm{kg}$, s.c. $)$ in the neck region between the shoulder blades. On days two and three, the procedure was repeated with an increased dose of capsaicin $(50 \mathrm{mg} / \mathrm{kg}$, s.c) (capsaicin-pretreated). Mice were left for 10 days before being intranasally inoculated with $\mathrm{IAV} \pm \mathrm{SLIGRL}$-amide, as described above. Control mice received injections of vehicle (1:1:8 vol/ $\mathrm{vol} / \mathrm{vol}$ of ethanol/Tween $80 /$ saline) (sham-pretreated). The protocol is shown in Fig. 3a. The effectiveness of the capsaicin desensitization protocol was determined in isometric tension recording studies by examining the capsaicin-induced relaxation responses in mouse isolated tracheal smooth muscle preparations.

\section{Isometric tension recording studies}

As previously demonstrated in our laboratories [31, 32] isometric tension recording studies can be used to determine the functionality of the sensory nerves within the mouse trachea. Groups of mice exposed to either capsaicin or saline (sham) mice were euthanased using pentobarbitone $(160 \mathrm{mg} / \mathrm{kg}$, i.p.). Tracheal segments were excised and suspended under a resting tension of $0.2 \mathrm{~g}$ in organ baths containing $20 \mathrm{ml}$ of Krebs bicarbonate solution $\left(117 \mathrm{mM} \mathrm{NaCl}, 5.36 \mathrm{mM} \mathrm{KCl}, 25 \mathrm{mM} \mathrm{NaHCO}{ }_{3}\right.$, $1.03 \mathrm{mM} \mathrm{KH} \mathrm{PO}_{4}, 0.57 \mathrm{mM} \mathrm{MgSO}{ }_{4} .7 \mathrm{H}_{2} \mathrm{O}, 2.5 \mathrm{mM}$ $\mathrm{CaCl}_{2}, 11.1 \mathrm{mM}$ D-glucose) maintained at $37^{\circ} \mathrm{C}$ and bubbled continuously with $5 \% \mathrm{CO}_{2}$ and $95 \% \mathrm{O}_{2}$. Changes in tension were recorded via a $751 \mathrm{mT}$ miniTOBs organ bath system (DMT, Aarhus, Denmark) connected to a Powerlab system (ADInstruments Pty Ltd., Castle Hill, Australia). Tracheal preparations were allowed to equilibrate for 30 mins and the viability of the tracheal smooth muscle was determined by cumulative exposure to a submaximal $(0.2 \mu \mathrm{M})$ and maximal $(10 \mu \mathrm{M})$ dose of carbachol. Tracheal segments were then repeatedly washed and allowed to rest for 20 mins. Preparations were precontracted using $1 \mu \mathrm{M}$ carbachol and upon reaching a plateau level of tension were exposed to a single $20 \mu \mathrm{M}$ bolus dose of capsaicin, and tension recordings continued until the peak response was obtained.

\section{Ex vivo infection of mouse isolated tracheal segments with IAV}

An airway explant perfusion system developed in our laboratories was used as a means of investigating the 
effects of selected peptides (SLIGRL-amide, BAM8-22, substance P, CGRP) on the capacity of IAV to infect and replicate in murine isolated airways, as previously described [7]. Briefly, tracheae harvested from untreated mice (male BALB/c mice at 7 to 8 weeks of age) were mounted onto an $18 \mathrm{G}$ blunted needle and perfused for at least half an hour at $37{ }^{\circ} \mathrm{C}$ with complete RPMI (cRPMI) medium at the rate of $100 \mu \mathrm{L} / \mathrm{min}$. Complete RPMI (cRPMI) medium consisted of RPMI 1640 medium (Gibco, Life Technologies-Thermo Fisher Scientific Inc, MA, USA) supplemented with $20 \mathrm{mM}$ HEPES, $2 \mathrm{mM}$ GlutaMAX $^{\mathrm{m}}, 2.0 \mu \mathrm{g} / \mathrm{mL}$ amphotericin B, $20 \mu \mathrm{g} / \mathrm{mL}$ gentamycin, and $1 \%$ foetal calf serum (FCS). Following this equilibration period, the perfusion was stopped and the tracheal lumen gently flushed first with $0.5 \mathrm{ml}$ of sterile saline, and then air, before being exposed to IAV (1/800 dilution of stock) \pm peptides for 15 mins, without perfusion. The lumen of the airway was then washed with $0.5 \mathrm{~mL}$ of sterile saline to remove unattached IAV and peptides, and perfused with cRPMI $\left(100 \mu \mathrm{L} / \mathrm{min}\right.$ at $\left.37^{\circ} \mathrm{C}\right)$ for $48 \mathrm{~h}$. Airway segments were removed from the needle and fixed in $2 \%$ paraformaldehyde (containing $0.2 \%$ picric acid) in PBS (pH 7.4), for $48 \mathrm{~h}$ at $4{ }^{\circ} \mathrm{C}$. Tissues were dehydrated (starting from $50 \%$ ethanol) and processed to paraffin wax on a standard $15 \mathrm{~h}$ cycle in a Leica ASP200S automated tissue processor (Wetzlar, Germany).

\section{Isolated airways from human lung}

The anti-IAV activity of SLIGRL-amide was also examined in small airway segments obtained from humans. Macroscopically normal samples of lung were obtained from patients undergoing lung surgery, usually for lung cancer. Segments of small airways (1-2 mm internal diameter) were dissected free from surrounding lung tissue and mounted onto the airway explant perfusion system. Perfused airways were exposed to IAV \pm SLIGRL-amide, as outlined above for mouse studies.

\section{Immunohistochemistry and imaging}

The presence of immunoreactive IAV in isolated trachea of IAV-exposed mice was visualised using standard immunohistochemical procedures, as previously reported [7]. Briefly, $5 \mu \mathrm{M}$ wax sections were dewaxed, rehydrated and permeablized with $1 \%$ Triton X-100 for 15 mins. Tissues were then blocked with $20 \%$ normal rabbit serum or $3 \%$ fish skin gelatin for $1 \mathrm{~h}$ and further exposed to avidin/biotin blocking as per manufacturer's instructions (Avidin/Biotin Blocking Kit; Vector Laboratories, Burlingame, CA). Goat anti-influenza A polyclonal antibody, $1 / 1000$ dilution $(5 \mu \mathrm{g} / \mathrm{ml}$ ) (Millipore Corporation, Billerica, MA); mouse anti-influenza A monoclonal antibody, $1 / 500$ dilution $(14.5 \mu \mathrm{g} / \mathrm{ml}$ ) (Abcam, Cambridge, ENG); normal goat IgG isotype control or normal mouse serum were applied to sections and incubated overnight at $4{ }^{\circ} \mathrm{C}$. After overnight incubation, sections were thoroughly washed in Tris-buffered saline (TBS) for one hour and endogenous peroxidase was quenched with $0.3 \% \mathrm{H}_{2} \mathrm{O}_{2}$ in TBS for 15 mins. The sections were then exposed to biotinylated rabbit anti-goat secondary IgG, 1/200 dilution (Vector Elite ABC kit; Vector Laboratories) or biotinylated rabbit anti-mouse IgG $\mathrm{F}(\mathrm{ab}) 2,1 / 200$ dilution $(3.65 \mu \mathrm{g} / \mathrm{ml})$ (Dako, Denmark) for 45 mins, followed by avidin-biotinhorseradish-peroxidase complex (Vector Elite $\mathrm{ABC}$ kit; Vector Laboratories) for 45 mins. The bound complex was visualised with diaminobenzidine (DAB, $0.4 \mathrm{mg} / \mathrm{ml}$ ). Sections were counterstained with Mayers haematoxylin and blued with Scotts Tap Water Substitute, washed and dehydrated through graded alcohols to xylene, then coverslipped with Depex mounting medium. Digital images were acquired on an Aperio ScanScope XT digital slide scanner (Leica (Aperio) Technologies, Vista, CA). Images represent at least three animals per treatment.

Visualisation of immunoreactive IAV in human isolated bronchioles was achieved following the same protocol as for mouse tissue (described above) but with the following modifications - the diluent for both the primary and secondary antibodies was $3 \%$ fish skin gelatin (FSG) (Sigma-Aldrich, St. Louis, MO) in $50 \mathrm{mM}$ Tris $+0.5 \mathrm{M} \mathrm{NaCl}+0.01 \%$ Triton-X-100. The blocking solution was $0.3 \mathrm{M}$ glycine in $3 \% \mathrm{FSG}$, and the wash buffer $(50 \mathrm{mM}$ Tris $+0.5 \mathrm{M} \mathrm{NaCl}+0.01 \%$ Triton-X100) contained $0.3 \mathrm{M}$ glycine. Avidin/Biotin blocking was not performed. All antibody concentrations, incubation and washing times, and visualisation with $\mathrm{DAB}$ remained the same.

\section{Quantitative analysis of immunoreactive IAV in mouse tracheal epithelium}

Digital images of sections stained for immunoreactive IAV (and visualised with diaminobenzidine), were generated using a ScanScope XT digital slide scanner (Leica (Aperio) Technologies, Vista, CA) and analysed using ImageScope v11.1.2. The Positive Pixel Count v9 algorithm (Aperio Technologies) was applied with input parameters of - colour saturation threshold (0.01), hue value (0.1) and intensity ranges for weak positive (175-220), positive (100-175) and strong positive $(0-175)$ pixels. These parameters were applied to an algorithm able to quantify diaminobenzidine positive sites of IAV expression, which were stained dark brown, as "strong positive pixels". The number of strong positive pixels (SPP) in the epithelium was counted by the algorithm and expressed as a percentage of the total pixels within the epithelial layer (\%SPP). \%SPP was calculated for each tracheal section and provided a means of quantifying changes in levels of IAV staining. 


\section{Attenuation of sensory nerve function in mouse isolated tracheal segments}

To investigate whether capsaicin-induced inhibition of sensory nerve function blocks the anti-IAV effects of SLIGRL-amide in vitro, mouse tracheas from naïve mice were connected to the airway explant perfusion system and then exposed to capsaicin $(20 \mu \mathrm{M})$ for 10 mins. Capsaicin-exposed preparations were washed and perfused with cRPMI for a further 10 mins prior to a standard $15 \mathrm{~min}$ exposure to IAV \pm SLIGRL-amide. Tracheal segments were washed and perfused for $48 \mathrm{~h}$ with cRPMI, and then processed to determine levels of immunohistochemical staining for IAV. Complementary isometric tension recording studies were performed to confirm that in vitro capsaicin pre-treatment inhibited TRPV1-mediated activation of airway sensory nerves.

\section{Mucin secretion studies}

The capacity of selected compounds to stimulate mucin release from epithelial stores of mucin was determined using the airway explant perfusion system. Following a $24 \mathrm{~h}$ period of perfusion with cRPMI, mouse isolated tracheal segments were exposed for 15 mins to SLIGRLamide $(200 \mu \mathrm{M})$, BAM8-22 $(25 \mu \mathrm{M})$, substance $\mathrm{P}$ $(1 \mu \mathrm{M})$, CGRP $(1 \mu \mathrm{M})$ or to the known mucin secretagogue ATP $(100 \mu \mathrm{M})$, or to saline. Tissues were then fixed in $2 \%$ paraformaldehyde (containing $0.2 \%$ picric acid) in PBS (pH 7.4), for $48 \mathrm{~h}$ at $4{ }^{\circ} \mathrm{C}$, processed to paraffin wax and $5 \mu \mathrm{m}$ sections stained with Alcian Blue-Periodic acid-Schiff's reagent (AB-PAS) to demonstrate the presence of mucins (the chief glycoprotein constituent of mucus) in the epithelial layer. The chosen concentration and period of exposure to ATP were based on those employed in mucin release studies conducted in mice [33, 34].

\section{Quantitative analysis of AB-PAS staining in mouse tracheal epithelium}

Digital images of AB-PAS stained sections were generated using a ScanScope XT digital slide scanner (Leica (Aperio) Technologies, Vista, CA) and analysed using ImageScope v11.1.2 and the Positive Pixel Count v9 algorithm (Aperio Technologies). Input parameters (color saturation threshold (0.04), hue value (0.1) and intensity ranges for weak positive (188-238), positive (176-188) and strong positive (0-176) pixels) were defined to generate an algorithm able to quantify AB-PAS-positive stores of mucin stained bright pink (as "strong positive pixels"). The number of strong positive pixels (SPP) in the epithelium was counted by the algorithm and expressed as a percentage of the total pixels within the epithelial layer (\%SPP). \%SPP was calculated for each tracheal section and provided a means of quantifying changes in levels of mucin staining.

\section{Materials}

SLIGRL-amide, BAM8-22, SLIGR-amide and CGRP8-37 were supplied by Auspep (Melbourne, Australia). Stock solutions were prepared in sterile high-purity water with subsequent dilutions made in sterile saline. The concentration, purity, and composition of the peptides were determined by high-performance liquid chromatography, mass spectrometry, and quantitative amino acid analysis. Carbachol (carbamylcholine chloride), ATP, indomethacin, atropine, propranolol, terbutaline, theophylline and L-703,606 were purchased from Sigma-Aldrich (St. Louis, MO), whilst RP-67580 ((3aR,7aR)-Octahydro-2-[1-imino-2(2-methoxy-phenyl)ethyl]-7,7-diphenyl-4H-isoindol), substance P, CGRP and L-733,060 were obtained from Tocris Bioscience (Ellisville, MO). Sodium pentobarbitone was supplied by Virbac Australia (Peakhurst, NSW), methoxyflurane by Medical Developments International Ltd (Springvale, Australia) and Schiff reagent by Australian Biostain (Vic, Australia).

\section{Statistical analysis}

Unless otherwise stated, grouped data are expressed as mean \pm SEM. Statistical comparisons between groups were made using one-way ANOVA with post-hoc testing (Holm procedure for all pairwise comparisons or Dunnett's test for comparisons to single control) using InVivoStat software. Differences between groups were considered statistically significant at $p<0.05$.

\section{Results}

\section{Effect of selected peptides on IAV infection in mice in} vivo

As shown in Fig. 1, BAL fluid recovered from the lungs of sham-inoculated mice (No IAV) consistently contained approximately 0.15 million cells, of which $99 \%$ were macrophages. In contrast, intranasal inoculation of IAV caused a marked influx of inflammatory cells into the lungs of mice, and by day 4 post-inoculation, the total BAL cell number was increased by approximately 10-fold, primarily due to a time-dependent influx of macrophages and neutrophils [7]. As expected, SLIGRLamide (activator of PAR-2 and MRGPRC11; [8]) dosedependently inhibited the IAV-induced increase in BAL leukocyte number (Fig. 1). BAM8-22, which activates MRGPRC11 but not PAR-2 [8]) also inhibited IAVinduced increases in BAL leukocyte number, and was approximately 10-times more potent than SLIGRLamide (Fig. 1). In contrast, SLIGR-amide (activator of PAR-2 but not MRGPRC11; $[8,35])$ did not inhibit IAVinduced increases in total BAL cell number at the highest dose tested (40 nmol/mouse) (Fig. 1). On face value, these data support the postulate that MRGPRC11 mediates the anti-IAV activities of SLGRL-amide and BAM822. However caution is required in this interpretation as 


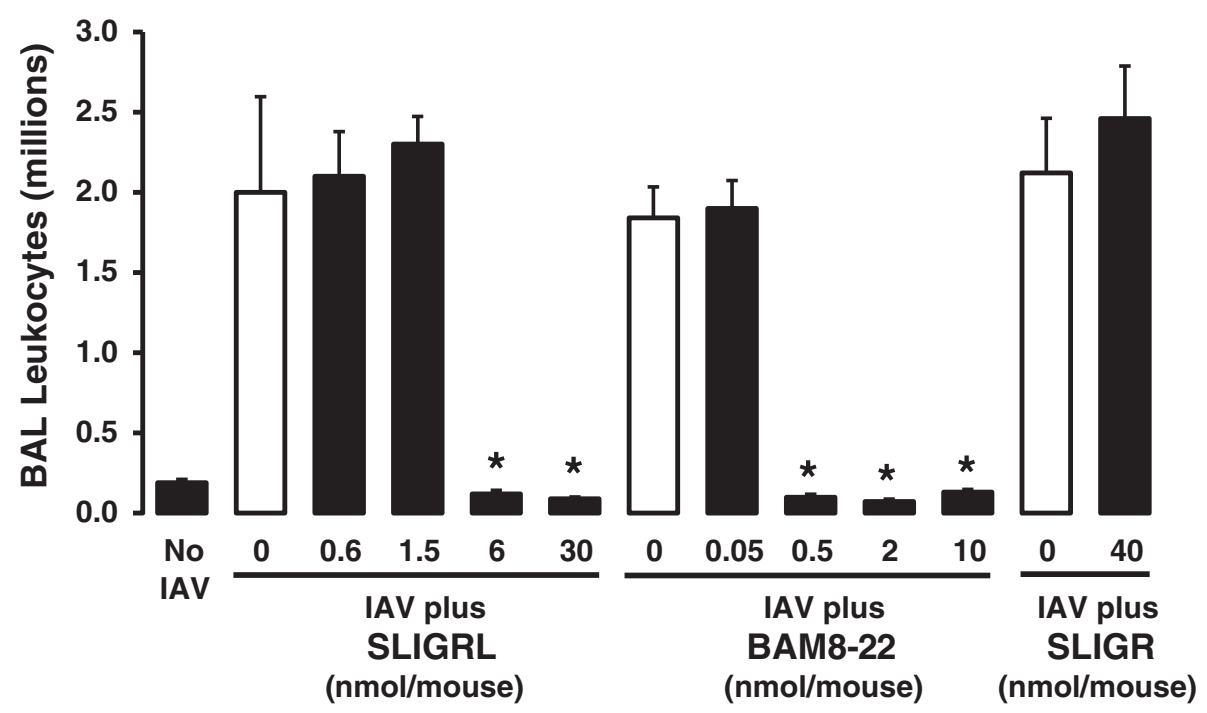

Fig. 1 Measurement of relative anti-IAV activities of SLIGRL-amide, BAM8-22 and SLIGR in mice by counting leukocytes recovered from BAL fluid. Mice were anaesthetised and intranasally inoculated with IAV in the presence or absence of selected doses of peptides. Four days later, BAL leukocyte numbers were determined for each mouse. Shown are mean \pm s.e.mean values from $4-10$ mice/group. ${ }^{*}$, indicates $P<0.05$ compared to respective IAV + saline control (one-way ANOVA)

SLIGRL-amide and BAM8-22 may not specifically activate MRGPRC11, and other receptors may be involved in mediating their anti-IAV effects.

Anti-IAV activity of SLIGRL-amide and BAM8-22 in Mrgprcluster $\Delta^{-/-}$and wild-type mice

To definitively evaluate the role of MRGPRC11 in the anti-IAV activities of SLIGRL-amide and BAM8-22, studies were conducted using Mrgpr-cluster $\Delta^{-/-}$mice that do not express MRCPRC11 [8, 24]. Intranasal inoculation of mice (Mrgpr-cluster ${ }^{-1-}$ and wild-type) with IAV (in the absence of peptides) was associated with a marked increase in total BAL cell number on day 4 post-inoculation (Fig. 2). As expected, both SLIGRLamide (6 and $30 \mathrm{nmol} / \mathrm{mouse}$ ) and BAM8-22 (0.5 and $2 \mathrm{nmol} /$ mouse) inhibited the IAV-induced increase in total BAL cell number in wild-type mice [24] (Fig. 2a and 2c). However, contrary to the hypothesis that MRGPRC11 mediates the anti-IAV effects of SLIGRLamide and BAM8-22, doses of these peptides that inhibited IAV-induced increases in total BAL cell number in BALB/c mice (Fig. 1a) and wild-type mice (Fig. 2), also exhibited anti-IAV activity in Mrgpr-cluster $\Delta^{-1-}$ mice (Fig. 2b and 2d). These findings provide strong evidence that the anti-IAV activities of either SLIGRL-amide or BAM8-22 are not mediated by MRGPRC11.

Role of sensory nerves in SLIGRL-amide-induced anti-IAV activity

Further studies were completed to evaluate the possibility that the anti-IAV activity of SLIGRL-amide was mediated by capsaicin-sensitive, neuropeptide-releasing airway sensory nerves. In these studies, the activity of SLIGRL-amide was investigated in mice in which sensory nerve function had been attenuated by either (1) chronic exposure to capsaicin or (2) administration of a neurokinin receptor antagonist.

Repeated daily exposure to capsaicin has previously been reported to cause chemical ablation of sensory nerves in mice $[27,29,36-38]$. In our studies, anaesthetized mice were exposed to capsaicin on 3 consecutive days (see Fig. 3a for protocol), and confirmation of the effectiveness of this in vivo protocol to induce airway sensory nerve dysfunction was obtained from isometric tension recording experiments (Fig. $3 \mathrm{~b}$ and 3c, lower panels). Tracheal smooth muscle segments from capsaicin-pre-treated mice did not relax in response to capsaicin, compared to the large relaxation response obtained in sham-pre-treated (no capsaicin) mice (Fig. 3b and $3 \mathrm{c}$ ), consistent with sensory nerve dysfunction.

Inoculation with IAV on day 13 of the protocol produced similar increases in BAL leukocytes in sham and capsaicin-pretreated mice (Fig. 3d and 3e). Moreover, IAV-induced increases in BAL leukocytes were inhibited by SLIGRL-amide in both sham (Fig. 3d) and capsaicinpretreated mice (Fig. 3e). These findings do not support a role for classic TRPV1-expressing, sensory $\mathrm{C}$-fibres in SLIGRL-amide-induced inhibition of IAV infectivity.

Some populations of activated airway sensory nerves release neuropeptides such as the tachykinin substance $\mathrm{P}$, which transmits responses via activation of neurokinin (NK) receptors. Consistent with this, NK1 receptor 

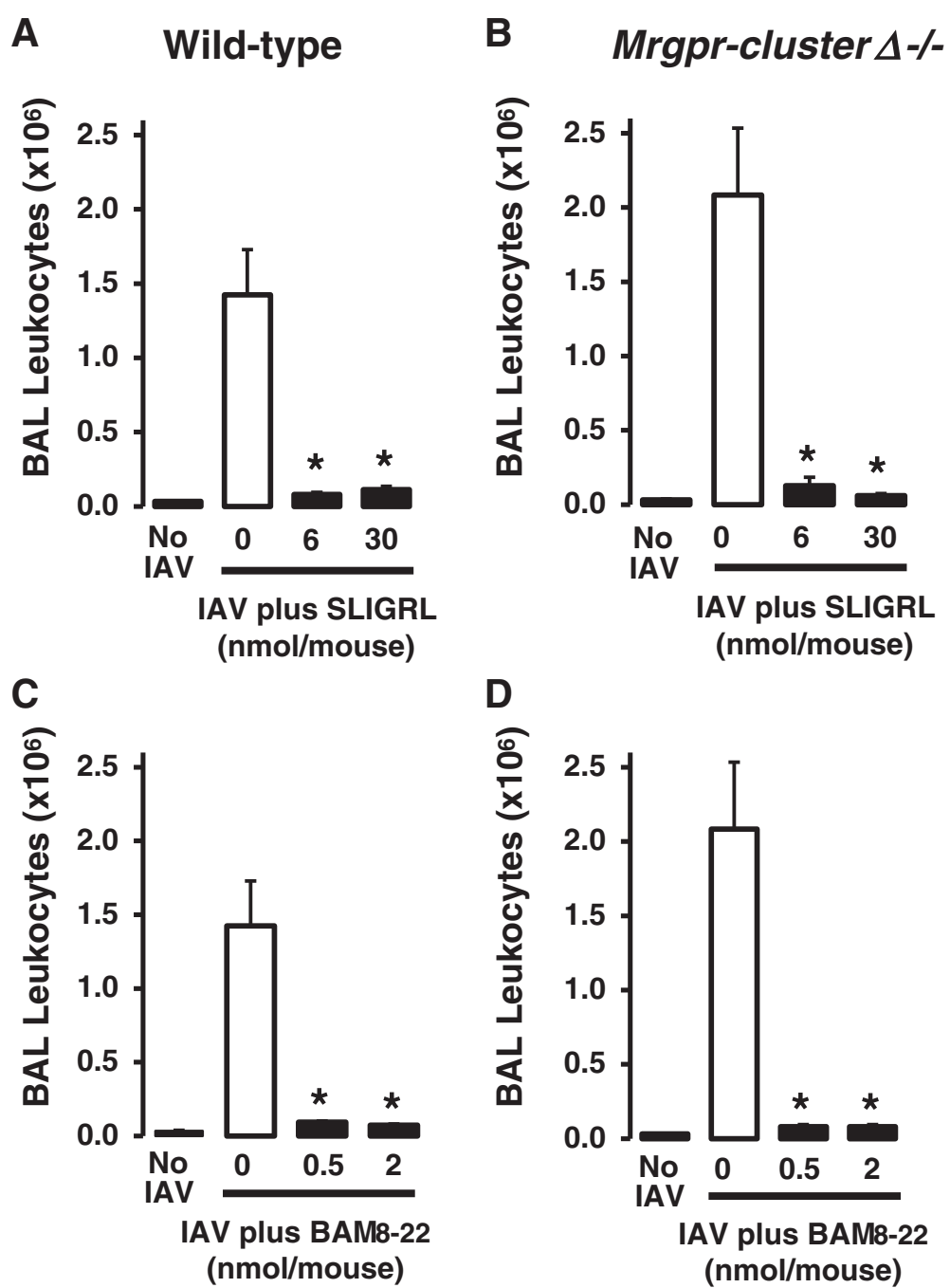

Fig. 2 Measurement of anti-IAV activities of SLIGRL-amide and BAM8-22 in wild-type and Mrgpr-cluster ${ }^{-/-}$mice by counting BAL leukocytes. Wild-type $(\mathbf{a}, \mathbf{c})$ and Mrgpr-cluster ${ }^{-/-}(\mathbf{b}, \mathbf{d})$ mice were anaesthetised and intranasally inoculated with IAV and selected doses of SLIGRL-amide $(\mathbf{a}, \mathbf{b})$ or BAM8-22 $(\mathbf{c}, \mathbf{d})$. Four days later, BAL was performed on each mouse and the total numbers of leukocytes recovered was determined. Shown are mean \pm s.e.mean of 3 mice per group. ${ }^{*}$, indicates $P<0.05$, compared to respective IAV + saline control (one-way ANOVA)

antagonists inhibit substance P-induced effects on microvascular leakage, mucus secretion and bronchomotor tone in the airways (see [39]). In the current study, administration of the NK1 receptor antagonist L-703,606 $(8.5 \mathrm{mg} / \mathrm{kg}$; $[40,41])$ did not block the capacity of SLIGRL-amide to inhibit IAV-induced increases in total BAL cell number in mice (Fig. 4), indicating that the actions of SLIGRL-amide were not mediated via activation of the sensory nerve substance P - NK1 receptor axis.

Effect of SLIGRL-amide and BAM8-22 on IAV infectivity in mouse isolated trachea ex vivo

Our laboratories have previously demonstrated that the antiviral activity of SLIGRL-amide observed in intact mice can be replicated in mouse isolated trachea ex vivo [7]. The novel ex vivo perfused tracheal system preserves tissue viability, architecture and microenvironment of the airways, and enables the study of the cellular mechanisms through which SLIGRL-amide inhibits IAV virus infection. Furthermore, this ex vivo perfusion system can be adapted to airways of other non-murine species, including human airways. In ex vivo studies, the levels of immunoreactive staining for IAV within the airway epithelium is the primary endpoint used to indicate IAV infectivity [7]. Extensive immunoreactive staining for IAV is indicative that the virus has proceeded through the sequential processes of viral attachment, endocytosis and replication. In the current study, a brief 15 min exposure of mouse isolated trachea to IAV resulted in the subsequent propagation of IAV within the epithelium over the ensuing $48 \mathrm{~h}$, as revealed by the presence of high levels of staining for immunoreactive IAV (Fig. 5a and 5b). In 


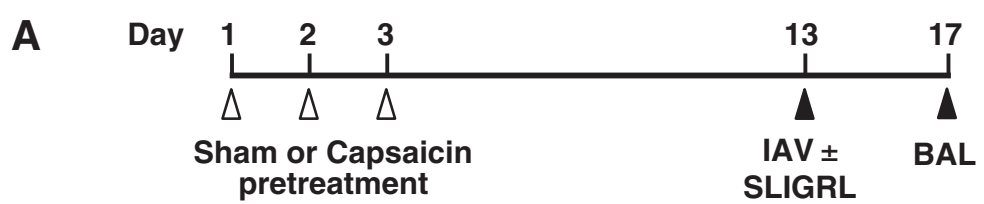

B Sham-pretreated

C Capsaicin-pretreated
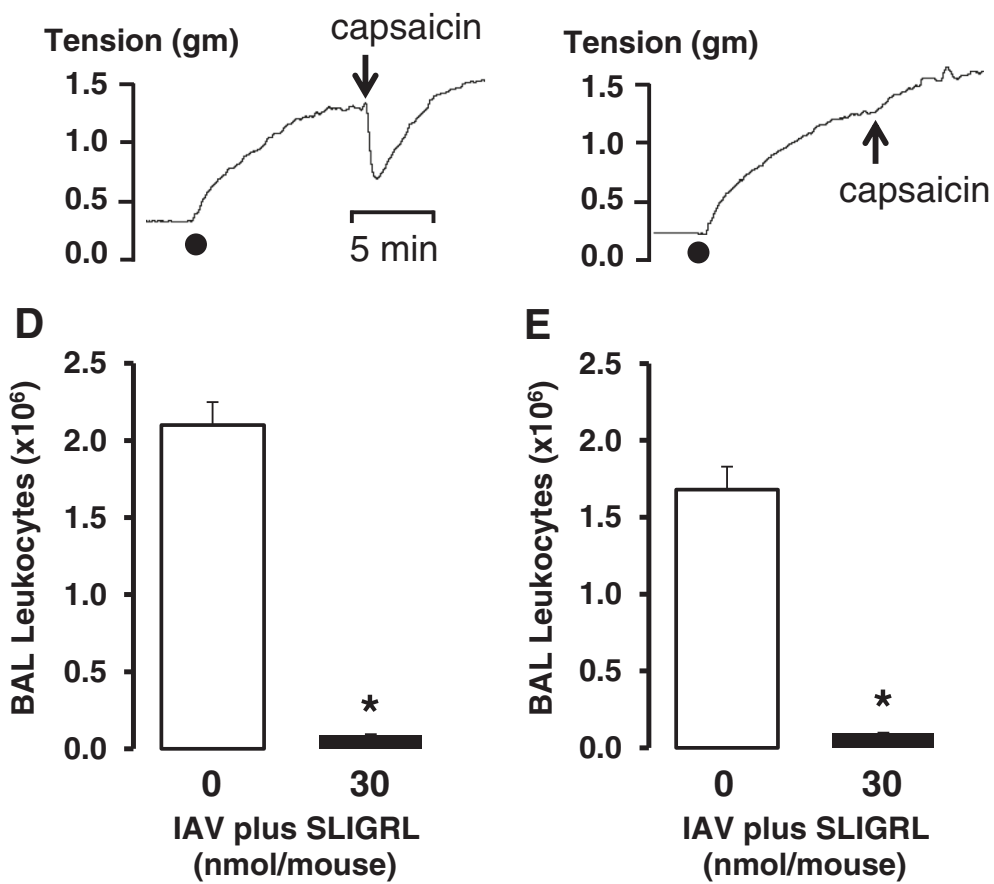

Fig. 3 Effect of sensory nerve dysfunction caused by in vivo capsaicin treatment on the anti-IAV activity of SLIGRL-amide in mice. a Protocol for capsaicin-induced dysfunction of sensory nerves. On 3 consecutive days, groups of mice were anaesthetised and injected subcutaneously with capsaicin or vehicle (Sham). Ten days later, mice were anaesthetised and intranasally inoculated with IAV in the presence or absence of SLIGRLamide. A further four days later, BAL was performed on each euthanased mouse and the total numbers of leukocytes recovered was determined. b \& c Isometric tension recordings performed on day 13 show that capsaicin pretreatment (using the protocol in a) abolishes the characteristic relaxant response to capsaicin $(10 \mu \mathrm{M})$, indicative of sensory nerve dysfunction. $\mathbf{d}$ \& e Total BAL leukocyte numbers recovered from IAV-inoculated mice that had been sham-pretreated (d) or pretreated with capsaicin to induce sensory nerve dysfunction. Shown are mean \pm s.e.mean of 3-7 mice per group. * , indicates $P<0.05$, compared to respective IAV + saline control (one-way ANOVA)

stark contrast, mouse tracheal segments exposed to SLIGRL-amide and BAM8-22 during the 15 min exposure period to IAV revealed negligible levels of immunohistochemical staining for IAV (Fig. 5a and 5b), indicating that IAV infectivity had been impaired by these peptides. Thus, as well as inhibiting IAV-induced increases in total BAL cell number in vivo (Fig. 1), SLIGRL-amide and BAM8-22, also inhibited IAV infectivity in mouse isolated tracheal segments (Fig. 5).

\section{Effect of sensory nerve activation on IAV infectivity}

Consistent with in vivo studies, the evidence obtained from studies using isolated mouse tracheal segments did not support the postulate that the anti-IAV effects of SLIGRL-amide were mediated by activation of capsaicinsensitive, neuropeptide-releasing sensory nerves. For example, the acute and direct activation of sensory nerves caused by a single $15 \mathrm{~min}$ exposure to capsaicin failed to inhibit IAV infectivity (Fig. 6a). Similarly, the exogenous application of selected sensory neuropeptides known to be released locally from activated sensory nerves (substance $P$ or CGRP at $1 \mu \mathrm{M}$ ), did not mimic the anti-IAV effects of SLIGRL-amide (Fig. 6b and 6c). Furthermore, neither an NK1 receptor antagonist (RP67580, $20 \mu \mathrm{M}$ ) nor a CGRP receptor antagonist (CGRP8-37, $10 \mu \mathrm{M}$ ) blocked SLIGRL-amide-induced inhibition of IAV infectivity in mouse tracheal segments (Fig. 6b and 6c).

Effect of SLIGRL-amide and ATP on release of epithelial mucin stores from mouse isolated tracheal segments Additional experiments were conducted to investigate the possibility that SLIGRL-amide stimulates the release 


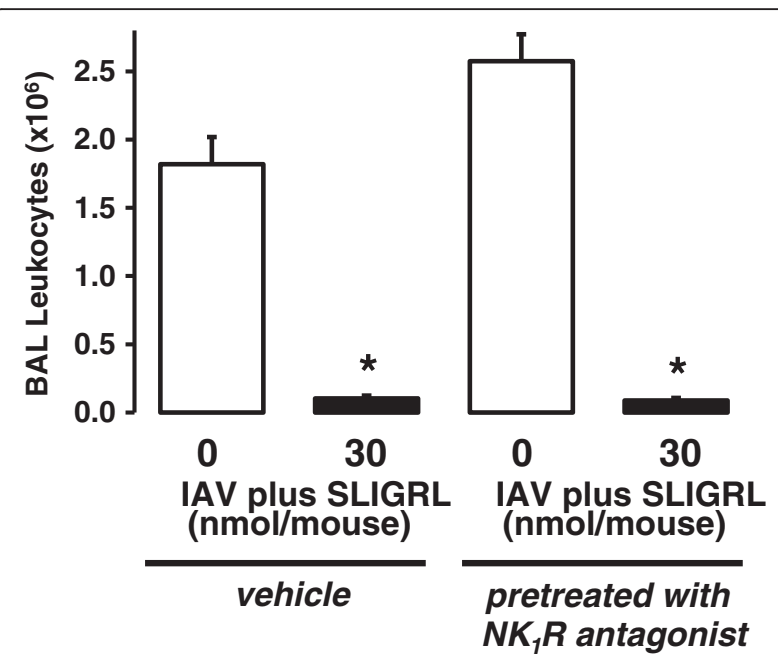

Fig. 4 Effect of in vivo administration of an NK1 receptor antagonist on the anti-IAV activity of SLIGRL-amide in mice. Groups of mice were injected with L-703,606 (8.5 mg/kg, i.p.) or vehicle (control), and 30 mins later intranasally inoculated with IAV in the presence or absence (saline) of SLIGRL-amide. A further four days later, BAL was performed on each euthanased mouse and the total numbers of leukocytes recovered was determined, as shown (mean \pm s.e.mean of 4-5 mice per group). ${ }^{*}$, indicates $P<0.05$ compared to respective IAV + saline control (one-way ANOVA)

of substances with anti-IAV activity directly from the airway epithelium. Consistent with this, exposure of tracheal segments to SLIGRL-amide was associated with a marked reduction in the levels of AB-PAS staining within the tracheal epithelium, indicative of mucin release (left-hand panels of Fig. 7a and 7b). Levels of AB-PAS staining were also reduced by the established secretagogue ATP and by BAM8-22, but not by either substance P or CGRP (Fig. 7b). Of particular interest, ATP also inhibited IAV infectivity in mouse isolated tracheal segments (right hand panels of Fig. 7a), similar to the effect produced by SLIGRL-amide.

\section{Effect of SLIGRL-amide on IAV infectivity in airways of human isolated airways}

As indicated above, an advantage of the ex vivo perfused airway system is that it can be readily adapted to enable the study of human airways. A 15 min exposure of human isolated bronchioles to IAV, followed by two days of perfusion with IAV-free cRPMI medium was associated with the development of high levels of staining for immunoreactive IAV within the epithelium, consistent with the replication of IAV (Fig. 8a). Co-incubation of IAV with SLIGRL-amide during the initial 15 min exposure period was associated with significantly suppressed the levels of epithelial IAV immunoreactivity in ex vivo segments of human bronchioles two days later $(\mathrm{P}=0.05$; Fig. 8b), consistent with findings obtained from in vivo and ex vivo studies using mice.

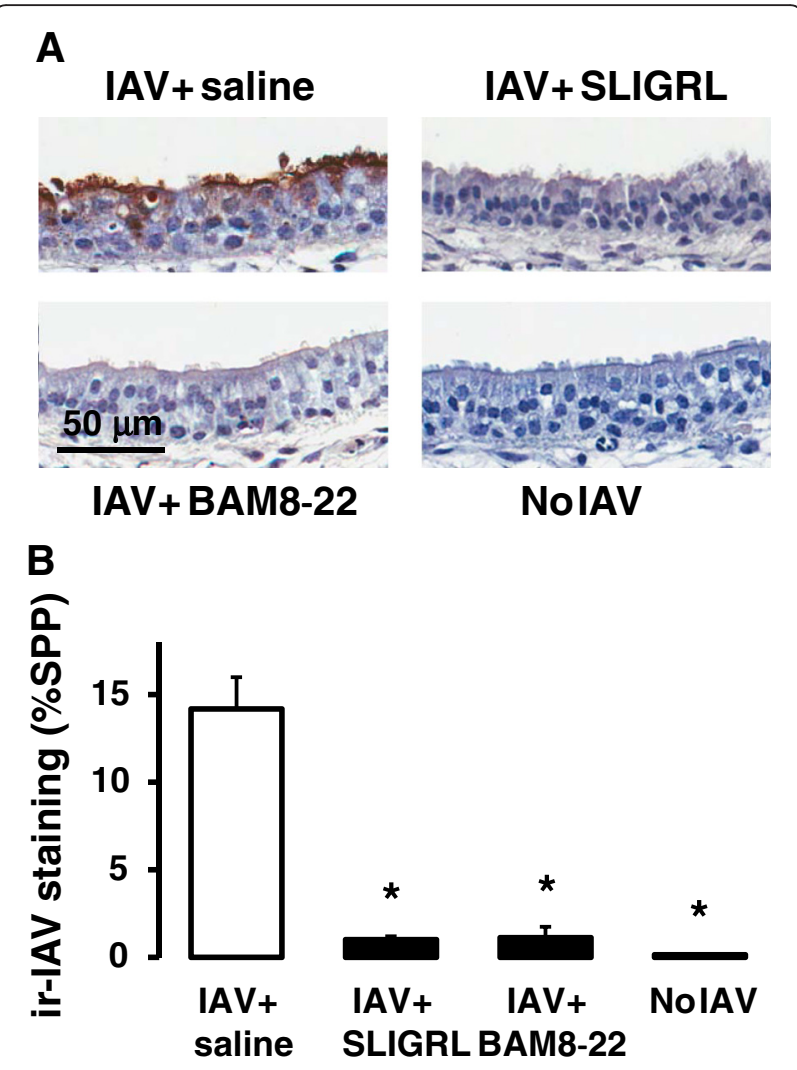

Fig. 5 Semiquantitative measurement of anti-IAV activities of SLIGRL-amide and BAM8-22 in mouse isolated tracheal segments by immunohistochemical staining of IAV nucleoprotein. a Immunohistochemical staining for IAV nucleoprotein in mouse tracheal sections. Mouse tracheal segments were mounted onto an airway explant perfusion system and incubated for 15 mins with IAV in the presence or absence of SLIGRL-amide or BAM8-22. Some tracheal segments were exposed to dilute allantoic fluid instead of IAV (No IAV). After $48 \mathrm{~h}$ of perfusion with media, segments were fixed, paraffinembedded, sectioned and immunohistochemically stained for IAV. Shown are representative images from at least 3 experiments. Bar $=$ $50 \mu \mathrm{m}$. b Levels of staining for immunoreactive-IAV in the epithelium of perfused trachea exposed to IAV in the absence ( $n=29$ trachea) or presence of SLIGRL-amide ( $n=8$ trachea) or BAM8-22 ( $n=4$ trachea). Some tracheal segments were exposed to dilute allantoic fluid instead of IAV (No IAV; $n=3$ trachea). Shown are mean levels of immunoreactive IAV staining (and standard error of the mean), expressed as \% of strong positive pixels, as outlined in the Methods section. ${ }^{*}$, indicates $P<0.05$, compared to IAV + saline control (one-way ANOVA)

\section{Discussion}

SLIGRL-amide activates murine PAR-2, and has been used for over twenty years to evaluate the role of PAR-2 activation in physiological and pathological processes [42-45]. SLIGRL-amide has also recently been shown to activate MRGPRC11, a G protein-coupled receptor expressed exclusively on sensory nerves [8], and to inhibit IAV infection in mice that lack PAR-2 [7]. The current study sought to determine whether the antiviral activity of SLIGRL-amide in mouse airways involved 


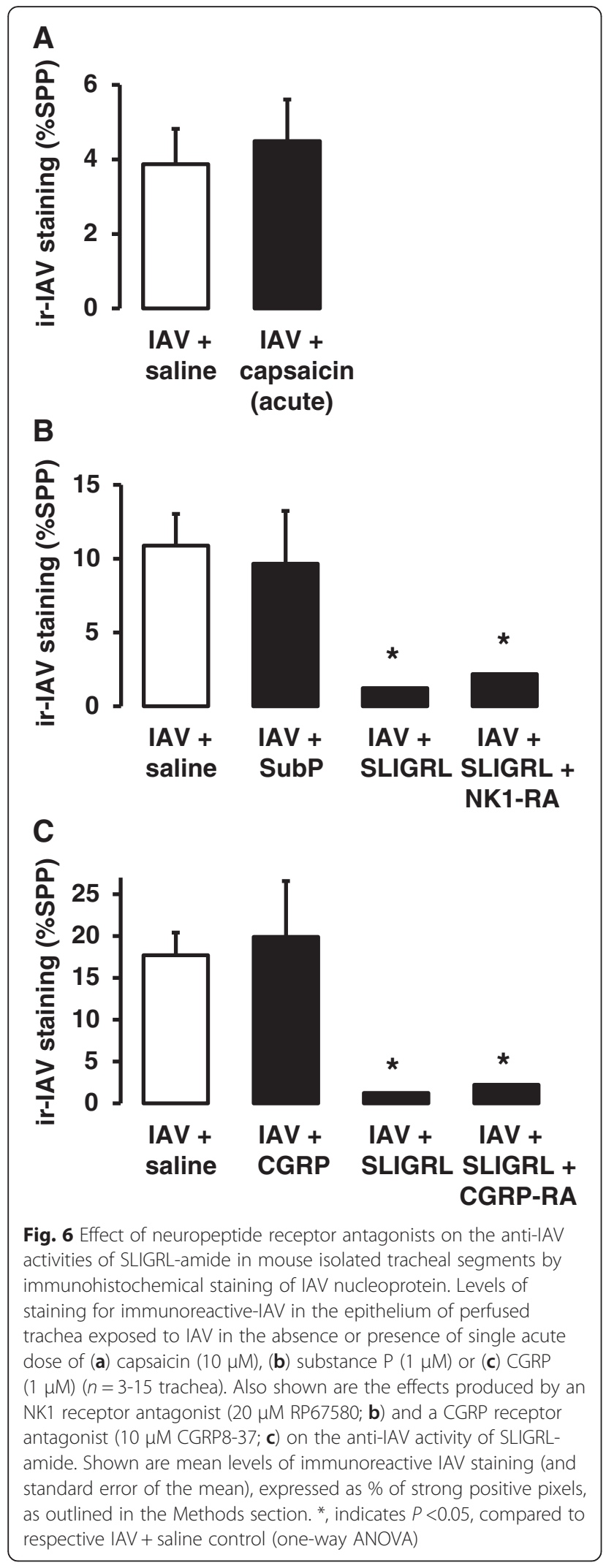

activation of MRGPRC11 and/or sensory nerves, and to determine whether SLIGRL-amide also inhibited IAV infectivity in human airways.

In the current study, IAV infectivity in intact mice and in mouse isolated tracheal segments was inhibited by BAM8-22, an established activator of MRGPRC11 $[8,13]$. Indeed, the observed 10-fold greater anti-IAV potency of BAM8-22 compared to SLIGRL-amide in mice was consistent with an action on MRGPRC11 $[8,10]$. However, both SLIGRL-amide and BAM8-22 were effective in preventing IAV infection in Mrgpr-cluster $\Delta^{-1-}$ mice that do not express MRGPRC11 [8]. These latter studies conducted in Mrgpr-cluster $\Delta^{-/}$mice provide compelling evidence that the anti-IAV activities of SLIGRL-amide and BAM8-22 were mediated independently of MRGPRC11. Additional pharmacologic studies were then undertaken to determine whether the anti-IAV properties of SLIGRLamide and BAM8-22 involved activation of a population of capsaicin-sensitive, peptidergic airway sensory nerves.

We hypothesised that if SLIGRL-amide inhibits IAV infection via activation of capsaicin-sensitive sensory nerves, then the anti-IAV activity of SLIGRL-amide should be suppressed following the chemical ablation of sensory nerves by repeated exposure of rodents to capsaicin $[27,29,36-38]$. However, the anti-IAV effects produced by SLIGRL-amide were preserved in mice that had been exposed to capsaicin on three consecutive days 10 days prior to inoculation with IAV, despite tracheal preparations obtained from these mice failing to produce a characteristic relaxation response to capsaicin [32]. Consistent with the findings of these in vivo studies, in vitro pre-treatment of mouse isolated tracheal segments to capsaicin rendered them unresponsive to subsequent challenges to capsaicin, but not to the anti-IAV actions of SLIGRL-amide. Furthermore, although NK1 receptors have previously been implicated in SLIGRL-amideinduced actions in mouse trachea [46] and small intestine [47], neither NK1 nor CGRP receptor antagonists blocked the anti-IAV activities of SLIGRL-amide, in vivo or ex vivo. Thus, our data do not support the explicit hypothesis that SLIGRL-amide inhibits IAV via activation of capsaicin-sensitive sensory nerves, or via the actions of the neuropeptides substance P or CGRP.

In a complementary series of experiments, we tested the postulate that if SLIGRL-amide inhibits IAV infection via activation of sensory nerves and local release of neuropeptides, then other agents that stimulate sensory nerves would mimic the anti-IAV actions of SLIGRL-amide. Capsaicin directly activates sensory nerve $\mathrm{C}$-fibres via stimulation of the highly expressed TRPV1 calcium ion channel. However, exposing mouse isolated tracheal segments to capsaicin together with IAV did not mimic the anti-IAV effects produced by SLIGRL-amide. In these experiments, 

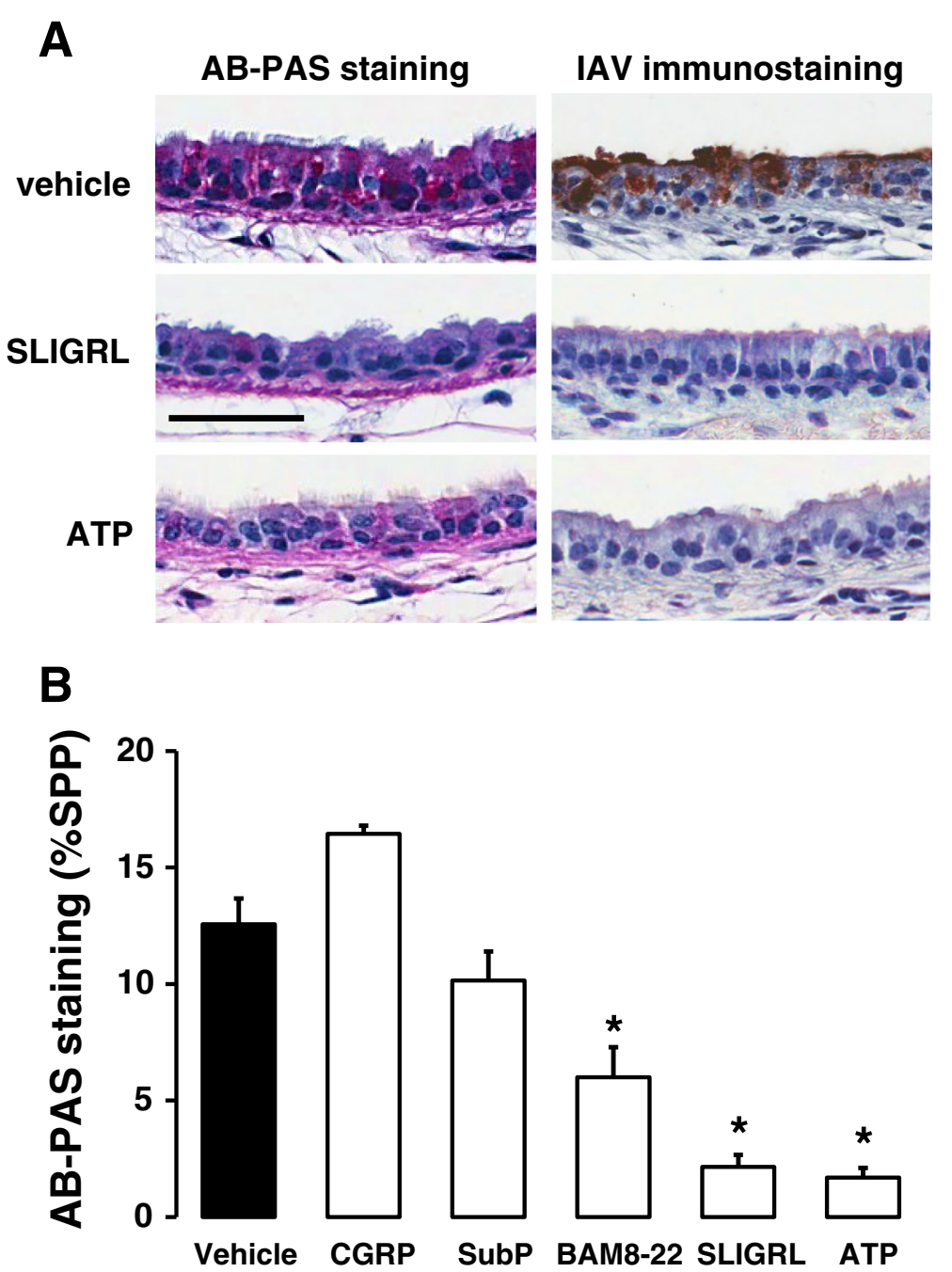

Fig. 7 Comparative effects of SLIGRL-amide and ATP on promoting mucin release and inhibiting IAV infectivity in mouse isolated tracheal segments. a Effect of SLIGRL-amide and the purinoceptor agonist ATP on levels of AB-PAS (left-hand panels) and IAV (right-hand panels) staining in sections of mouse trachea. In AB-PAS experiments, mouse isolated tracheal segments were mounted onto the explant perfusion system and pre-perfused for $24 \mathrm{~h}$, and then incubated for $15 \mathrm{~min}$ with saline, SLIGRL-amide or ATP. Segments were fixed, paraffin-embedded, sectioned and stained with AB-PAS. In IAV immunohistochemical staining experiments, tracheal segments were mounted onto the explant perfusion system and incubated for 15 min with IAV in the presence of absence of saline, SLIGRL-amide or ATP. After two days of perfusion with media, segments were fixed, paraffin-embedded, sectioned and immunostained for IAV. Shown are representative images from at least 3 experiments. Bar $=50 \mu m$. $\mathbf{b}$ Residual levels of AB-PAS staining, expressed as \%SPP (strong positive pixels), within the epithelium of mouse isolated tracheal segments following a 15 min exposure to saline (control, white fill) or selected compounds (black fill) ( $n=4-8$ tracheal segments per group). Luminal exposure to SLIGRL-amide, BAM8-22 and ATP, but not CGRP or substance $P$ (SubP), stimulated a reduction in epithelial AB-PAS staining, consistent with mucin secretion. *, $P<0.05$, compared to vehicle (one-way ANOVA, Dunnett's posthoc test)

capsaicin was used at a concentration $(10 \mu \mathrm{M})$ that induced large relaxation responses in mouse isolated tracheal preparations [32]. These responses were blocked by a TRPV1 antagonist (capsazepine) and an NK1 receptor antagonist (L-733060), consistent with sensory nerve activation [32]. In addition, if the anti-IAV effects of SLIGRLamide were mediated via the actions of substance $\mathrm{P}$ and/ or CGRP released from activated sensory nerves, then the exogenous application of these neuropeptides should also inhibit IAV infectivity. However, neither substance P nor
CGRP, at concentrations known to induce maximal receptor activation, inhibited IAV infectivity in mouse isolated tracheal preparations. Together, these findings do not support the postulate that activation of capsaicin-sensitive, neuropeptide-releasing sensory nerves at the time of IAV exposure significantly inhibits IAV infectivity in the epithelium of mouse isolated trachea.

Sensory nerve $\mathrm{C}$ fibre function has been reported to influence the response of the host to respiratory tract insults including bacterial endotoxin, mycoplasma and 

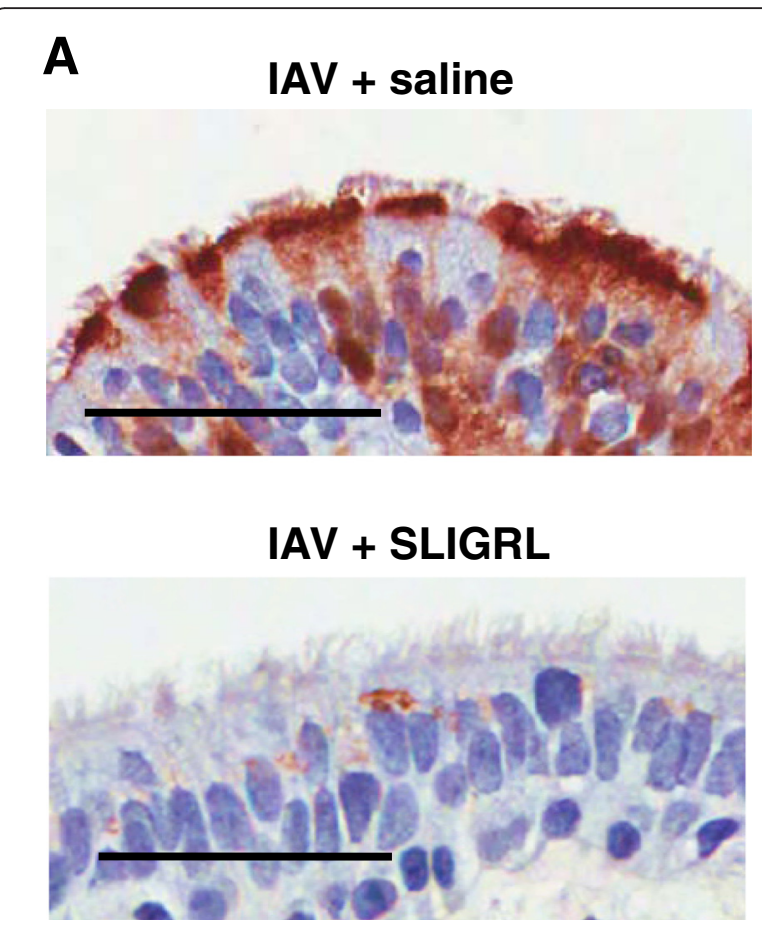

B

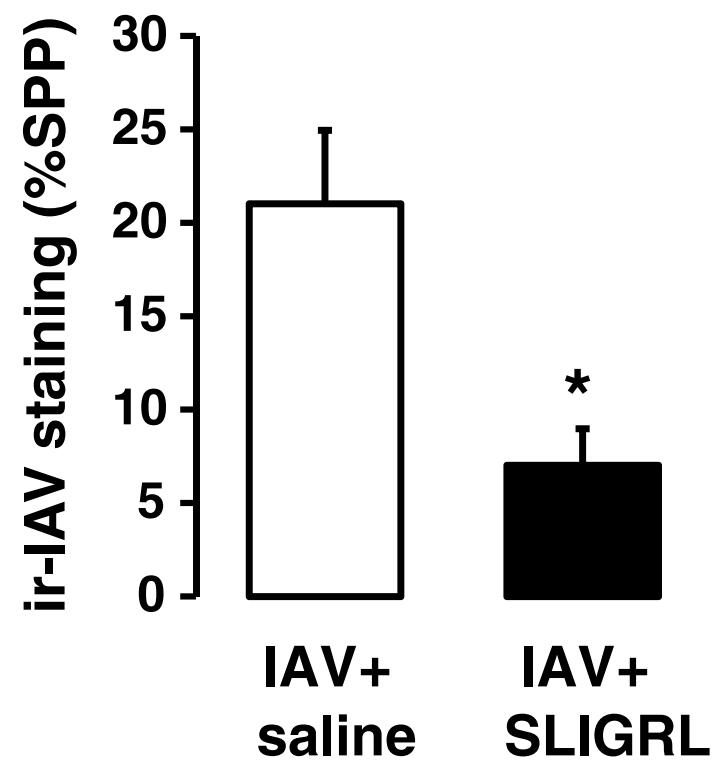

Fig. 8 Semiquantitative measurement of anti-IAV activities of SLIGRLamide in human isolated bronchiolar segments by immunohistochemical staining of IAV nucleoprotein. a Immunohistochemical staining of IAV in sections of human isolated bronchiolar segments exposed to IAV in the absence (upper image) or presence of SLIGRL-amide (lower image), for $15 \mathrm{~min}$. After $48 \mathrm{~h}$ of perfusion with media, segments were fixed, paraffinembedded, sectioned and immunohistochemically stained for IAV. Bar = $50 \mu \mathrm{m}$. b Levels of staining for immunoreactive IAV nucleoprotein in the bronchiolar epithelium of perfused human airways exposed to saline or SLIGRL-amide. Shown are representative images from at least 4-9 experiments using airways from different donors. ${ }^{*}$, indicates $P<0.05$, compared to IAV + saline control (one-way ANOVA)

environmental toxicants [27, 37, 38, 48-50], however little is known of the consequence of sensory nerve activation or sensory nerve dysfunction on influenza infection. In the current study, stimulation of sensory nerves with capsaicin during an initial period of IAV exposure did not prevent the subsequent propagation of IAV within the epithelium of mouse isolated airways. These findings indicate that local release of neuropeptides following sensory nerve activation does not markedly impact on the capacity of IAV to enter and replicate in airway epithelial cells.

The current study has established that SLIGRL-amide inhibits IAV infectivity in vivo and ex vivo via mechanisms that are independent of MRGPRC11 and of capsaicin-sensitive sensory nerves, and also independent of the sensory neuropeptides substance P and CGRP and their receptors. However, it is important to note that vagal bronchopulmonary $\mathrm{C}$-fibers in the mouse are heterogeneous - a substantial fraction of C-fiber afferent nerves in the mouse respiratory system are capsaicininsensitive [51], and that a fraction of capsaicin-sensitive C-fibers are non-peptidergic [20]. Thus, we cannot exclude the possibility that SLIGRL-amide may exert its antiviral activities through actions on sub-populations of capsaicin-insensitive, nonpeptidergic neurons. Nevertheless, the current investigation builds on our previous studies that demonstrate SLIGRL-amide does not inhibit IAV infectivity via PAR-2, by direct antiviral or by immunomodulatory processes [7]. Of particular interest, the current study has shown that the anti-IAV effects of SLIGRL-amide observed in murine airways extend to human airways, although further studies are required to identify its specific molecular target.

SLIGRL-amide and related peptides have been reported to directly stimulate secretory pathways in the airways [46, 52-54]. Importantly, components of airway secretions, including the mucin MUC5AC exert protective roles against influenza A virus [55]. Thus, the release of endogenous antiviral substances in mucus may contribute to the anti-IAV activity of SLIGRL-amide. In the current study, SLIGRL-amide promoted the release of intracellular mucins from mouse tracheal epithelium, as 
determined from microscopic imaging of AB-PASstained airway sections. The purinergic receptor agonist ATP, an established key secretagogue for airway epithelium [56-58], also promoted the release of intracellular mucins from mouse isolated tracheal epithelium, and moreover, inhibited IAV infectivity. These findings provide preliminary evidence that SLIGRL-amide may inhibit IAV infectivity by stimulating the secretion of endogenous substances with anti-IAV activity. Nevertheless, it remains to be determined whether the anti-IAV activity of SLIGRL-amide involves the secretion of sialic acid-rich mucins [55], or other anti-IAV molecules such as cationic host defence peptides ( $\beta$-defensins, cathelicidins) [59] or phospholipids such as palmitoyl-oleoylphosphatidylglycerol (POPG) [60].

\section{Conclusion}

The current study using a combination of in vivo and ex vivo approaches provides compelling evidence that the anti-IAV activity of SLIGRL-amide in murine airways occurs independently of the sensory nerve receptor MRGPRC11 and of neuropeptide release from TRPV1expressing sensory nerves. Preliminary data show that both SLIGRL-amide and ATP release airway secretions and inhibit IAV infection, raising the possibility that SLIGRL-amide inhibits IAV infectivity via the release of antiviral substances from the airway epithelium. Additional release and intervention studies, particularly in human airways, will provide invaluable insight into the molecular target and cellular signalling processes through which SLIGRL-amide inhibits IAV infectivity.

\section{Acknowledgements}

The authors acknowledge the facilities, and the scientific and technical assistance of the Australian Microscopy \& Microanalysis Research Facility at the Centre for Microscopy, Characterisation \& Analysis, The University of Western Australia, a facility funded by The University of Western Australia, and the State and Commonwealth Governments of Australia.

\section{Authors' contributions}

Participated in research design: AC, TM, PM, LH, XD, PH. Conducted experiments: AC, TM, LH. Performed data analysis: AC, TM, PH. Wrote or contributed to writing of manuscript: AC, TM, PM, XD, PH. All authors read and approved the final manuscript.

\section{Competing interests}

The authors declare that they have no competing interests.

\section{Author details}

${ }^{1} S c h o o l$ of Medicine and Pharmacology, University of Western Australia, Crawley, WA 6009, Australia. ${ }^{2}$ School of Anatomy, Physiology \& Human Biology, University of Western Australia, Crawley 6009, WA, Australia. ${ }^{3}$ Howard Hughes Medical Institute, Johns Hopkins University School of Medicine, Baltimore, MD 21205, USA.

Received: 5 February 2016 Accepted: 15 May 2016 Published online: 23 May 2016

\section{References}

1. Influenza (Seasonal) Fact Sheet No.211 (2014) [http://www.who.int/ mediacentre/factsheets/fs211/en/\#] Accessed on 27 Jan 2016.
2. Beigel J, Bray M. Current and future antiviral therapy of severe seasonal and avian influenza. Antiviral Res. 2008;78:91-102.

3. Hayden F. Developing new antiviral agents for influenza treatment: what does the future hold? Clin Infect Dis. 2009;48 Suppl 1:S3-S13.

4. Bright RA, Medina MJ, Xu X, Perez-Oronoz G, Wallis TR, Davis XM, Povinelli L, Cox NJ, Klimov Al. Incidence of adamantane resistance among influenza A (H3N2) viruses isolated worldwide from 1994 to 2005: a cause for concern. Lancet. 2005;366:1175-81.

5. Li TC, Chan MC, Lee N. Clinical Implications of Antiviral Resistance in Influenza. Viruses. 2015;7:4929-44.

6. Spanakis N, Pitiriga V, Gennimata V, Tsakris A. A review of neuraminidase inhibitor susceptibility in influenza strains. Expert Rev Anti Infect Ther. 2014; 12:1325-36.

7. Betts RJ, Mann TS, Henry PJ. Inhibitory influence of the hexapeptidic sequence SLIGRL on influenza A virus infection in mice. J Pharmacol Exp Ther. 2012;343:725-35.

8. Liu Q, Weng HJ, Patel KN, Tang Z, Bai H, Steinhoff M, Dong X. The distinct roles of two GPCRs, MrgprC11 and PAR2, in itch and hyperalgesia. Sci Signal. 2011:4:ra45.

9. Lee MG, Dong X, Liu Q, Patel KN, Choi OH, Vonakis B, Undem BJ. Agonists of the MAS-related gene (Mrgs) orphan receptors as novel mediators of mast cell-sensory nerve interactions. J Immunol. 2008;180:2251-5.

10. Solinski HJ, Gudermann T, Breit A. Pharmacology and signaling of MASrelated G protein-coupled receptors. Pharmacol Rev. 2014;66:570-97.

11. Dong X, Han S, Zylka MJ, Simon Ml, Anderson DJ. A diverse family of GPCRs expressed in specific subsets of nociceptive sensory neurons. Cell. 2001;106:619-32.

12. Grazzini E, Puma C, Roy MO, Yu XH, O'Donnell D, Schmidt R, Dautrey S, Ducharme J, Perkins M, Panetta R. Sensory neuron-specific receptor activation elicits central and peripheral nociceptive effects in rats. Proc Natl Acad Sci U S A. 2004:101:7175-80.

13. Han SK, Dong X, Hwang JI, Zylka MJ, Anderson DJ, Simon MI. Orphan G protein-coupled receptors MrgA1 and $\mathrm{MrgC11}$ are distinctively activated by RF-amide-related peptides through the Galpha q/11 pathway. Proc Natl Acad Sci U S A. 2002:99:14740-5.

14. Lembo PM, Grazzini E, Groblewski T, O'Donnell D, Roy MO, Zhang J, Hoffert C, Cao J, Schmidt R, Pelletier M, et al. Proenkephalin A gene products activate a new family of sensory neuron-specific GPCRs. Nat Neurosci. 2002;5:201-9.

15. Burstein ES, Ott TR, Feddock M, Ma JN, Fuhs S, Wong S, Schiffer HH, Brann MR, Nash NR. Characterization of the Mas-related gene family: structural and functional conservation of human and rhesus MrgX receptors. Br J Pharmacol. 2006;147:73-82.

16. Guan Y, Liu Q, Tang Z, Raja SN, Anderson DJ, Dong X. Mas-related Gprotein-coupled receptors inhibit pathological pain in mice. Proc Natl Acad Sci U S A. 2010;107:15933-8.

17. Verhein $K C$, Fryer $A D$, Jacoby DB. Neural control of airway inflammation. Curr Allergy Asthma Rep. 2009;9:484-90.

18. Kollarik M, Ru F, Brozmanova M. Vagal afferent nerves with the properties of nociceptors. Auton Neurosci. 2010;153:12-20.

19. Potenzieri C, Meeker S, Undem BJ. Activation of mouse bronchopulmonary Cfibres by serotonin and allergen-ovalbumin challenge. J Physiol. 2012;590:5449-59.

20. Nassenstein C, Taylor-Clark TE, Myers AC, Ru F, Nandigama R, Bettner W, Undem BJ. Phenotypic distinctions between neural crest and placodal derived vagal C-fibres in mouse lungs. J Physiol. 2010;588:4769-83.

21. Canning BJ, Spina D: Sensory nerves and airway irritability. Handb Exp Pharmacol. 2009:194:139-183.

22. Lamb JP, Sparrow MP. Three-dimensional mapping of sensory innervation with substance $p$ in porcine bronchial mucosa: comparison with human airways. Am J Respir Crit Care Med. 2002;166:1269-81.

23. White MR, Helmerhorst EJ, Ligtenberg A, Karpel M, Tecle T, Siqueira WL, Oppenheim FG, Hartshorn KL. Multiple components contribute to ability of saliva to inhibit influenza viruses. Oral Microbiol Immunol. 2009;24:18-24.

24. Liu Q, Tang Z, Surdenikova L, Kim S, Patel KN, Kim A, Ru F, Guan Y, Weng $H J$, Geng Y, et al. Sensory neuron-specific GPCR Mrgprs are itch receptors mediating chloroquine-induced pruritus. Cell. 2009;139:1353-65.

25. Williams K, Mackenzie JS. Influenza infections during pregnancy in the mouse. J Hyg (Lond). 1977;79:249-57.

26. Fazekas De St Groth S, White DO. An improved assay for the infectivity of in influenza viruses. J Hyg (Lond). 1958:56:151-62.

27. Buckley TL, Nijkamp FP. Airways hyperreactivity and cellular accumulation in a delayed-type hypersensitivity reaction in the mouse. Modulation by capsaicin-sensitive nerves. Am J Respir Crit Care Med. 1994;149:400-7. 
28. Kawabata A, Oono Y, Yonezawa D, Hiramatsu K, Inoi N, Sekiguchi F, Honjo M, Hirofuchi M, Kanke T, Ishiwata H. 2-Furoyl-LIGRL-NH2, a potent agonist for proteinase-activated receptor-2, as a gastric mucosal cytoprotective agent in mice. Br J Pharmacol. 2005;144:212-9.

29. Morris JB, Symanowicz PT, Olsen JE, Thrall RS, Cloutier MM, Hubbard AK. Immediate sensory nerve-mediated respiratory responses to irritants in healthy and allergic airway-diseased mice. J Appl Physiol (1985). 2003;94:1563-71.

30. Scheerens H, Buckley TL, Muis T, Van Loveren H, Nijkamp FP. The involvement of sensory neuropeptides in toluene diisocyanate-induced tracheal hyperreactivity in the mouse airways. Br J Pharmacol. 1996;119:1665-71.

31. Cheah EY, Burcham PC, Mann TS, Henry PJ. Acrolein relaxes mouse isolated tracheal smooth muscle via a TRPA1-dependent mechanism. Biochem Pharmacol. 2014:89:148-56.

32. Taylor SJ, Mann TS, Henry PJ. Influence of influenza A infection on capsaicininduced responses in murine airways. J Pharmacol Exp Ther. 2012;340:377-85.

33. Agrawal A, Rengarajan S, Adler KB, Ram A, Ghosh B, Fahim M, Dickey BF. Inhibition of mucin secretion with MARCKS-related peptide improves airway obstruction in a mouse model of asthma. J Appl Physiol (1985). 2007;102:399-405.

34. Evans CM, Williams OW, Tuvim MJ, Nigam R, Mixides GP, Blackburn MR, DeMayo FJ, Burns AR, Smith C, Reynolds SD, et al. Mucin is produced by clara cells in the proximal airways of antigen-challenged mice. Am J Respir Cell Mol Biol. 2004;31:382-94.

35. Hollenberg MD, Saifeddine M. al-Ani B: Proteinase-activated receptor-2 in rat aorta: structural requirements for agonist activity of receptor-activating peptides. Mol Pharmacol. 1996;49:229-33.

36. Cattaruzza F, Cenac N, Barocelli E, Impicciatore M, Hyun E, Vergnolle N, Sternini C. Protective effect of proteinase-activated receptor 2 activation on motility impairment and tissue damage induced by intestinal ischemia/ reperfusion in rodents. Am J Pathol. 2006;169:177-88.

37. Elekes K, Helyes Z, Nemeth J, Sandor K, Pozsgai G, Kereskai L, Borzsei R, Pinter E, Szabo A, Szolcsanyi J. Role of capsaicin-sensitive afferents and sensory neuropeptides in endotoxin-induced airway inflammation and consequent bronchial hyperreactivity in the mouse. Regul Pept. 2007;141: 44-54.

38. Morris JB, Wilkie WS, Shusterman DJ. Acute respiratory responses of the mouse to chlorine. Toxicol Sci. 2005;83:380-7.

39. Steinhoff MS, von Mentzer B, Geppetti P, Pothoulakis C, Bunnett NW. Tachykinins and their receptors: contributions to physiological control and the mechanisms of disease. Physiol Rev. 2014;94:265-301.

40. Chauhan VS, Kluttz JM, Bost KL, Marriott I. Prophylactic and therapeutic targeting of the neurokinin-1 receptor limits neuroinflammation in a murine model of pneumococcal meningitis. J Immunol. 2011;186:7255-63.

41. Yang $Y$, Yan $M$, Zhang $H$, Wang $X$. Substance $P$ participates in immunemediated hepatic injury induced by concanavalin $A$ in mice and stimulates cytokine synthesis in Kupffer cells. Exp Ther Med. 2013;6:459-64.

42. Nystedt S, Emilsson K, Wahlestedt C, Sundelin J. Molecular cloning of a potential proteinase activated receptor. Proc Natl Acad Sci U S A. 1994;91: 9208-12.

43. Ossovskaya VS, Bunnett NW. Protease-activated receptors: contribution to physiology and disease. Physiol Rev. 2004;84:579-621.

44. Ramachandran R, Noorbakhsh F, Defea K, Hollenberg MD. Targeting proteinase-activated receptors: therapeutic potential and challenges. Nat Rev Drug Discov. 2012;11:69-86.

45. Rothmeier AS, Ruf W. Protease-activated receptor 2 signaling in inflammation. Semin Immunopathol. 2012;34:133-49.

46. Abey HT, Fairlie DP, Moffatt JD, Balzary RW, Cocks TM. Protease-activated receptor-2 peptides activate neurokinin-1 receptors in the mouse isolated trachea. J Pharmacol Exp Ther. 2006;317:598-605.

47. Zhao A, Shea-Donohue T. PAR-2 agonists induce contraction of murine small intestine through neurokinin receptors. Am J Physiol Gastrointest Liver Physiol. 2003;285:G696-703.

48. Bowden JJ, Baluk P, Lefevre PM, Schoeb TR, Lindsey JR, McDonald DM. Sensory denervation by neonatal capsaicin treatment exacerbates Mycoplasma pulmonis infection in rat airways. Am J Physiol. 1996;270:L393-403.

49. Raemdonck K, de Alba J, Birrell MA, Grace M, Maher SA, Irvin CG, Fozard JR, O'Byrne PM, Belvisi MG. A role for sensory nerves in the late asthmatic response. Thorax. 2012;67:19-25.

50. Schelegle ES, Walby WF. Vagal afferents contribute to exacerbated airway responses following ozone and allergen challenge. Respir Physiol Neurobiol. 2012;181:277-85.
51. Kollarik M, Dinh QT, Fischer A, Undem BJ. Capsaicin-sensitive and -insensitive vagal bronchopulmonary C-fibres in the mouse. J Physiol. 2003:551:869-79.

52. Kunzelmann K, Sun J, Markovich D, Konig J, Murle B, Mall M, Schreiber R. Control of ion transport in mammalian airways by protease activated receptors type 2 (PAR-2). FASEB J. 2005;19:969-70.

53. Lee HJ, Yang YM, Kim K, Shin DM, Yoon JH, Cho HJ, Choi JY. Proteaseactivated receptor 2 mediates mucus secretion in the airway submucosal gland. PLoS One. 2012;7, e43188.

54. Lin KW, Park J, Crews AL, Li Y, Adler KB. Protease-activated receptor-2 (PAR-2) is a weak enhancer of mucin secretion by human bronchial epithelial cells in vitro. Int J Biochem Cell Biol. 2008;40:1379-88

55. Ehre C, Worthington EN, Liesman RM, Grubb BR, Barbier D, O'Neal WK, Sallenave JM, Pickles RJ, Boucher RC. Overexpressing mouse model demonstrates the protective role of Muc5ac in the lungs. Proc Natl Acad Sci U S A. 2012;109:16528-33.

56. Adler KB, Tuvim MJ, Dickey BF. Regulated mucin secretion from airway epithelial cells. Front Endocrinol (Lausanne). 2013;4:129.

57. Fahy JV, Dickey BF. Airway mucus function and dysfunction. N Engl J Med. 2010;363:2233-47

58. Kreda SM, Okada SF, van Heusden CA, O'Neal W, Gabriel S, Abdullah L, Davis CW, Boucher RC, Lazarowski ER. Coordinated release of nucleotides and mucin from human airway epithelial Calu-3 cells. J Physiol. 2007;584: 245-59.

59. Gwyer Findlay E, Currie SM, Davidson DJ. Cationic host defence peptides: potential as antiviral therapeutics. Biodrugs. 2013;27:479-93.

60. Numata M, Kandasamy P, Nagashima Y, Posey J, Hartshorn K, Woodland D, Voelker DR. Phosphatidylglycerol suppresses influenza A virus infection. Am J Respir Cell Mol Biol. 2012;46:479-87.

\section{Submit your next manuscript to BioMed Central and we will help you at every step:}

- We accept pre-submission inquiries

- Our selector tool helps you to find the most relevant journal

- We provide round the clock customer support

- Convenient online submission

- Thorough peer review

- Inclusion in PubMed and all major indexing services

- Maximum visibility for your research

Submit your manuscript at www.biomedcentral.com/submit
Biomed Central 